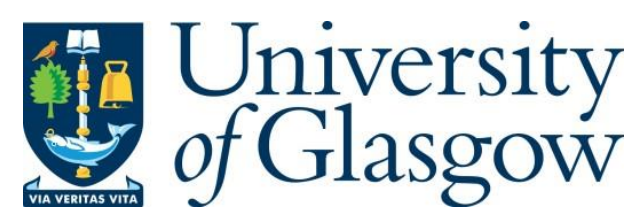

Boothroyd, R.J., Williams, R.D., Barrett, B., Hoey, T.B., Tolentino, P.L.M., Perez, J.E., Guardian, E., David, C.P. and Yang, X. (2020) Detecting and quantifying morphological change in tropical rivers using Google Earth Engine and image analysis techniques. In: River Flow 2020: 10th Conference on Fluvial Hydraulics, Delft, Netherlands, 07-10 Jul 2020, pp. 1013-1021. ISBN 9780367627737.

There may be differences between this version and the published version. You are advised to consult the publisher's version if you wish to cite from it.

http://eprints.gla.ac.uk/222881/

Deposited on: 8 September 2020

Enlighten - Research publications by members of the University of Glasgow http://eprints.gla.ac.uk 


\title{
Detecting and quantifying morphological change in tropical rivers using Google Earth Engine and image analysis techniques
}

\author{
R.J. Boothroyd, R.D. Williams and B. Barrett \\ School of Geographical and Earth Sciences, University of Glasgow, United Kingdom
}

T.B. Hoey

Brunel University London, United Kingdom

P.L.M. Tolentino, J.E. Perez, E. Guardian and C.P. David

National Institute of Geological Sciences, University of Philippines, Philippines

X.Yang

Department of Geological Sciences, University of North Carolina, United States

\begin{abstract}
Various tools have been demonstrated that are capable of delineating and characterizing river channels, but efforts to scale these analyses up to multi-temporal, catchmentscale applications are in their infancy. Here, we use Google Earth Engine (GEE) to extract the active channel (including the wetted channel and unvegetated, alluvial deposits) from the Bislak and Cagayan Rivers in the Philippines. Using temporal composites of Landsat 5, 7 and 8 satellite imagery over $\sim 30$ years, the active channel is resolved at annual intervals. The active channel occurrence frequency is mapped using image analysis techniques to detect large-scale planimetric change. Quantification of active channel centerline change is achieved using the RivMAP toolbox. Over a $135 \mathrm{~km}$ reach of the Cagayan River, the average migration rate was $17.5 \mathrm{~m} \cdot \mathrm{a}^{-1}$ ranging from $7.7 \mathrm{~m} \cdot \mathrm{a}^{-1}$ in 1988 to $37.0 \mathrm{~m} \cdot \mathrm{a}^{-1}$ in 2005 . The findings quantify patterns of dynamism in tropical river systems and demonstrate the utility of GEE in fluvial geomorphology applications.
\end{abstract}

\section{INTRODUCTION}

Remote sensing is transforming what we map, measure and analyze in river science and fluvial geomorphology (Marcus and Fonstad, 2010). A number of tools have been developed to measure channel width and centerlines from satellite imagery e.g. RivWidth/RivWidthCloud (Pavelsky and Smith, 2008, Yang et al., 2019) and RivaMAP (Isikdogan et al., 2017) then quantify multi-temporal planform change e.g. SCREAM (Rowland et al., 2016), RivMAP (Schwenk et al., 2017) and PyRIS (Monegaglia et al., 2018). Often these tools are applied to delineate and characterize the wetted river channel. From a fluvial geomorphology perspective, however, the geomorphologically active channel, i.e. the zone where the river can vertically and laterally adjust (Gurnell et al., 2016), is of potentially greater significance than the stage- and dischargedependent wetted channel. Google Earth Engine (GEE) could enable the spatial and temporal upscaling of such tools (Gorelick et al., 2017, Fryirs et al., 2019).

In settings such as the Philippines, where sediment delivery rates are globally high (Syvitski et al., 2005) and rates of floodplain development adjacent to rivers are intense, risks arising from geomorphologically active rivers need to be assessed and incorporated into flood risk management. For example, as channels migrate, they erode their floodplain, potentially resulting in property losses and the failure of critical infrastructure (e.g. bridges). Compared with temperate regions, less is known about the behavior of tropical rivers. Previous analyses of river planform change in the Philippines found meanders migrating at rates of up to $30 \mathrm{~m} \cdot \mathrm{a}^{-1}$ (Dingle et al., 2019). These rapid rates imply that in large catchments $\left(>10^{3} \mathrm{~km}^{2}\right)$, meander migration rates may be up to an order of magnitude greater than in temperate region catchments of equivalent size (Dingle et al., 2019). Multi-temporal, catchment-scale applications are needed to further test this result and investigate the fundamental controls on tropical river morphodynamics and their evolutionary trajectories.

In this paper, we describe a semi-automated GEE workflow to extract the active channel from publicly available satellite imagery. The active channel is defined to include both the wetted 
channel and unvegetated, alluvial deposits (so does not include vegetated islands). The definition is not based on, or sensitive to, river stage or discharge (Manners et al., 2014). We resolve the annual active channel for two tropical rivers in north Luzon, the Philippines, between 1987 and 2019 to: (i) detect large-scale planimetric change in the Bislak River; and, (ii) quantify the reach averaged migration rate for the Cagayan River. The findings quantify patterns of dynamism in tropical river systems and demonstrate the utility of GEE in fluvial geomorphology applications.

\section{METHODOLOGY}

\subsection{Study Sites}

Two tropical river systems on Luzon Island (Philippines) were selected for analysis (Figure 1). Both are prone to extreme meteorological events (typhoons, tropical cyclones) that can generate geomorphically effective flows from highly elevated water and sediment discharges.

The Bislak River is the main trunk channel of the Bislak catchment $\left(\sim 600 \mathrm{~km}^{2}\right)$, sourced in the Cordillera Central Mountains. It has a Type I climate, having distinct dry and wet seasons (Tolentino et al., 2016). The active channel of the Bislak River is narrow $(<200 \mathrm{~m})$ and laterally confined in the upper catchment, whereas the active channel widens $(\sim 500 \mathrm{~m})$ and the planform becomes more braided/wandering towards the downstream outlet.

The Cagayan River is the main trunk channel of the Cagayan catchment $\left(\sim 27,000 \mathrm{~km}^{2}\right)$, the largest catchment in the Philippines. Notable tributaries include the Chico and Pinacanauan de Ilagan Rivers. It has a Type III climate, having less pronounced seasonality than the Bislak River (Tolentino et al., 2016). The active channel of the Cagayan River is wider (> $1000 \mathrm{~m}$ towards the downstream outlet), exhibiting alternating single and multithreaded reaches.

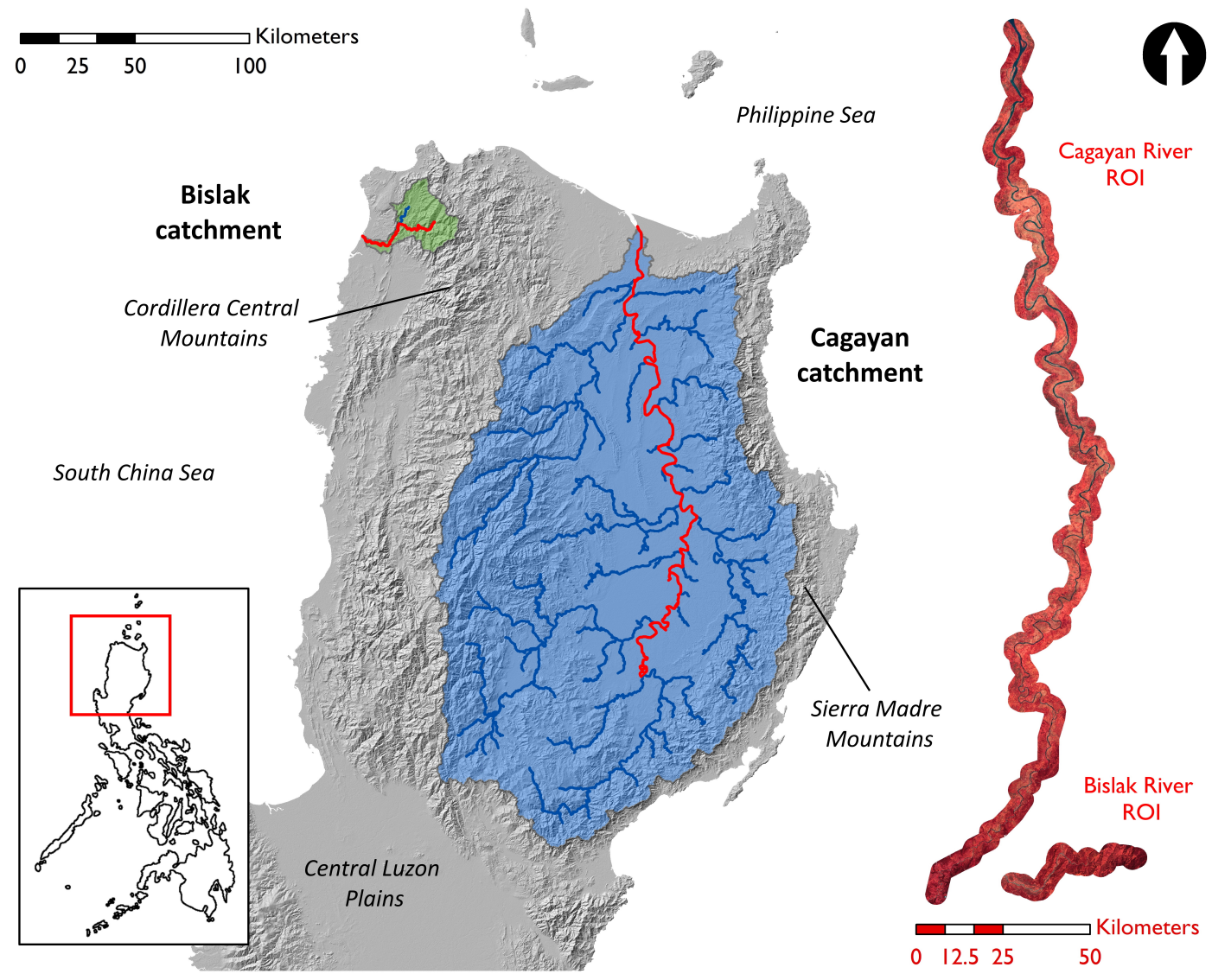




\subsection{Google Earth Engine (GEE) overview}

Google Earth Engine (GEE) is a cloud-based computing platform for processing very large geospatial datasets (Gorelick et al., 2017). Tens of petabytes of publicly available remotely sensed imagery (e.g. Landsat and Sentinel collections) and other datasets (e.g. Shuttle Radar Topography Mission) are freely accessible through the GEE data catalog. To date, GEE has been successfully applied to map and quantify long-term changes in surface waters at the global-scale (Donchyts et al., 2016, Pekel et al., 2016). Applications of GEE in the fluvial geomorphology context are more limited, although river avulsion dynamics (Edmonds et al., 2016) and wetted river widths (Yang et al., 2019) have been assessed.

\subsection{Google Earth Engine (GEE) workflow}

For this application, a semi-automated GEE workflow was developed to extract the active channel from Landsat imagery. The workflow uses all available Landsat surface reflectance (SR) imagery (including: Landsat 5 Thematic Mapper (TM), Landsat 7 Enhanced TM+ and Landsat 8 Operational Land Imager (OLI) and Thermal Infrared Sensor (TIRS); nominal resolution 30 $\mathrm{m})$ for the time-period $1987-2019$. Region of interest (ROI) polygons were first drawn for each main trunk channel where the width of the active channel was consistently $>200 \mathrm{~m}$ (Figure 1). Key stages of the workflow are shown in Figure 2 and described below:

a) Time and ROI filter - annual image collections were built using all available Landsat imagery (Bislak River $n=1427$, Cagayan River $n=1380$ ). The image collections were spatially filtered by the bounds of the ROI (Figure 1). The number of images contained in annual image collections varied because of the operational histories of the Landsat satellites (Bislak River: $\min =13, \max =70$, mean $=44.6$; Cagayan River: $\min =9, \max =72$, mean $=43.1)$. No imagery was available for 2012 .

b) Cloud masking procedure - for each image, the CFmask algorithm was applied to mask cloud and cloud shadow pixels (Foga et al., 2017).

c) Temporal compositing - a median reducer was applied to aggregate the cloud-masked images in the annual image collection, generating an individual annual image (an annual temporal composite). Sensitivity analysis was undertaken to test the effect of different reducer percentiles. For instance, the $25^{\text {th }}$ percentile represented 'greener' conditions than the $75^{\text {th }}$ percentile when visualized in RGB space.

d) Water classification - the spectral-based classification of Zou et al. (2018) was used to classify water pixels in the annual temporal composite image, producing a binary water mask. The method has reported accuracy of $97 \%$ across the contiguous United States and visual analysis suggested that the approach performed well here (e.g. Figure 2d). The water classification uses multiple spectral indices including the modified normalized difference water index, MNDWI, normalized difference vegetation index, NDVI and enhanced vegetation index, EVI.

e) Active channel classification - the same multiple spectral indices as above were used to classify the active channel pixels, producing a binary active channel mask. The active channel boundary was enforced by excluding vegetated pixels. The approach is similar to Monegaglia et al. (2018), although no additional benefit was observed by including the SWIR 2 band (used for emerging sediment bar detection). Active channel pixels were classified using relational operators where MNDWI $\geq-0.4$ and NDVI $\leq 0.2$. An NDVI threshold of 0.2 is established in the literature for dense riparian vegetation (Bertoldi et al., 2011).

f) Binarization, data export and noise removal - the binary water and active channel masks were combined to a single image (i.e. union). The final binary image was exported to Google Drive as a GeoTIFF file. Noise removal was undertaken using the image processing toolbox in MATLAB, with patches of disconnected pixels representing small objects $\left(<0.09 \mathrm{~km}^{2}\right.$ or 100 pixels for the Bislak River; $<0.9 \mathrm{~km}^{2}$ or 1000 pixels for the Cagayan River) removed from the final binary image. No further cleaning was undertaken. 
a)

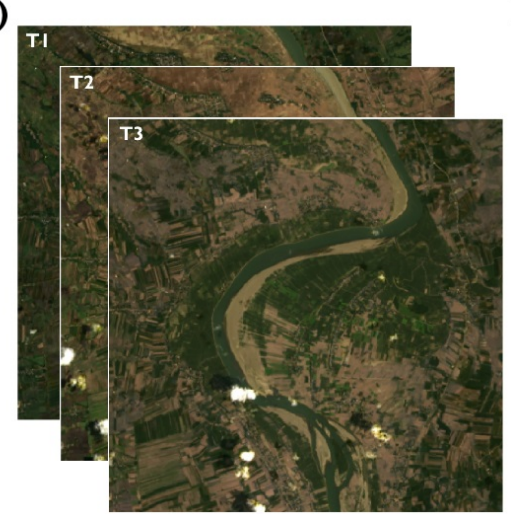

c)

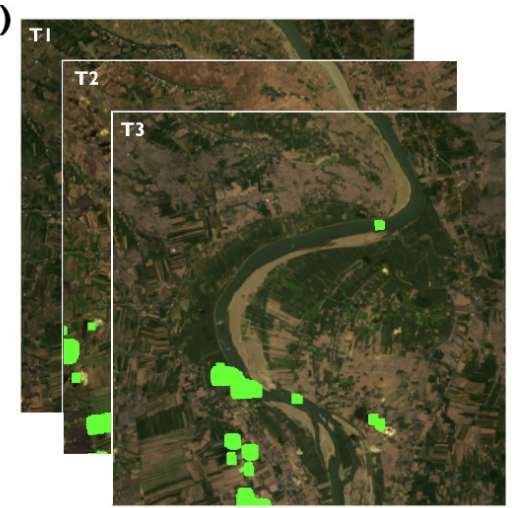

b)
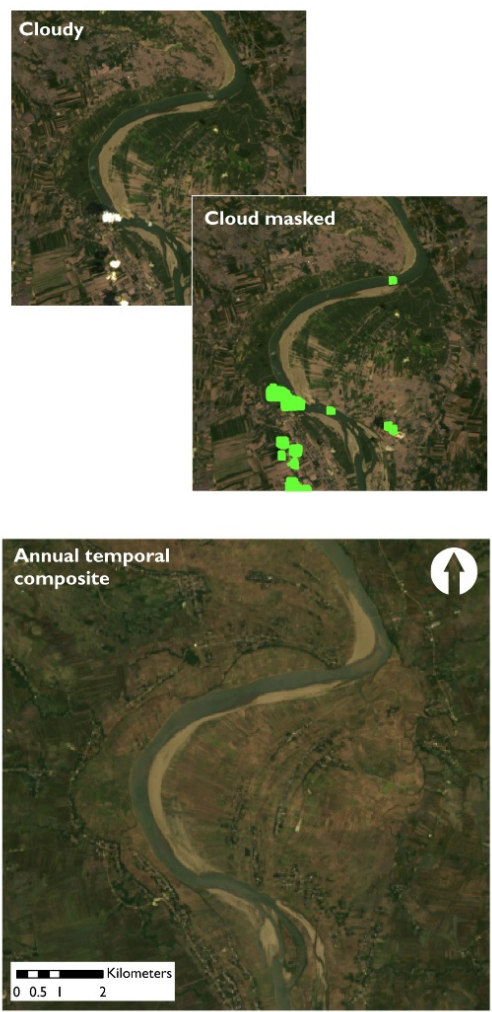

d)
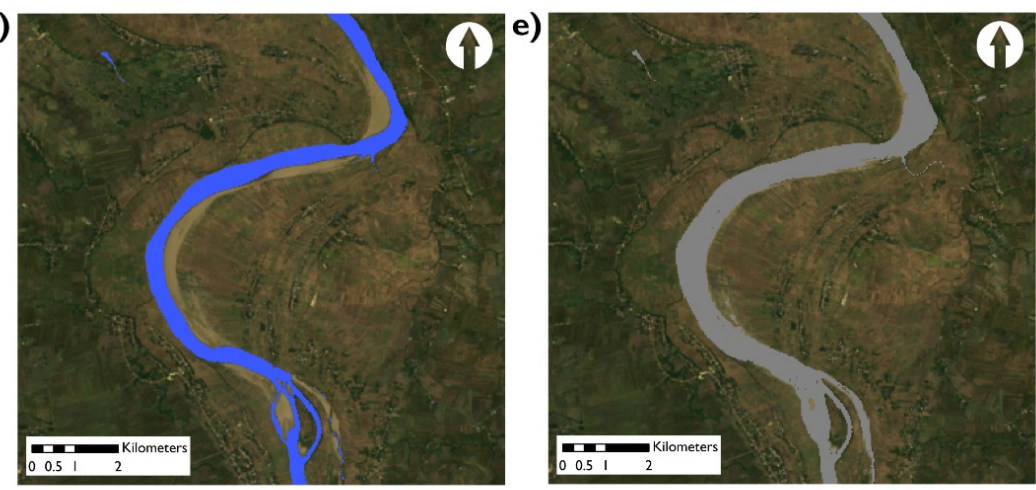

f)

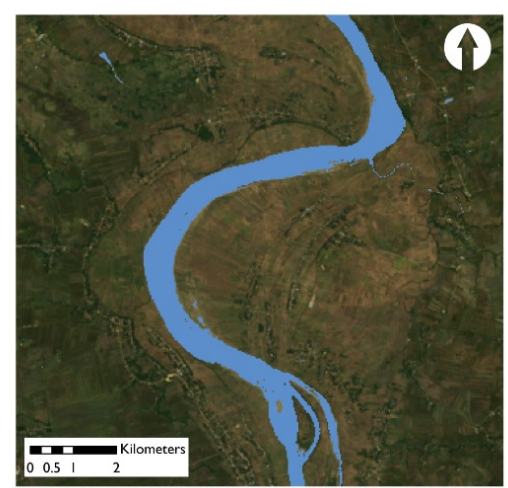

Figure 2. Google Earth Engine (GEE) workflow for active channel classification. Example from the Cagayan River (17 $\left.21^{\prime} 26.3^{\prime \prime N} 121^{\circ} 46^{\prime} 41.1^{\prime \prime E}\right)$. This includes: (a) time and ROI filter; (b) cloud masking procedure following Foga et al. (2017); (c) temporal composition of cloud masked images; (d) water classification following Zou et al. (2018); (e) active channel classification; and, (f) binarization and data export. The water mask largely reinforces the active channel mask. No noise removal has been applied to the above images. 


\subsection{Active channel change}

Analysis of active channel change is limited to river reaches where the binarized active channel masks was continuous (i.e. the mask did not fragment at the $30 \mathrm{~m}$ pixel resolution). The reaches were close to the downstream outlet, with lengths of $15 \mathrm{~km}$ for the Bislak River and $135 \mathrm{~km}$ for the Cagayan River. Active channel change is investigated through: (i) quantification of active channel occurrence frequency and (ii) centerline analysis using the RivMAP toolbox.

\section{RESULTS}

\subsection{Active channel occurrence frequency}

First, we focus on the $15 \mathrm{~km}$ reach of the Bislak River to detect large-scale planimetric change. The position of the active channel has shifted through time (e.g. Figure 3). Active river channel occurrence, the frequency with which a pixel is classified as active channel between 1987 and 2019, is mapped to visualize channel dynamics (Figure 4). The map enables interpretation of geomorphic processes, with the active channel shown to wander in the downstream section and infrequent activation/disconnection of a secondary chute channel observed around the middle section. Towards the downstream section of the study reach, the active channel occurrence is high $(>80 \%)$. Towards the upstream section, however, the active channel occurrence is lower $(\sim 50 \%)$. Detailed visual inspection of annual binary masks showed fragmentation towards the upstream end of the reach (12/32 had discontinuous binary masks). This is likely a function of the narrow width $(<200 \mathrm{~m})$ of the active channel relative to pixel size $(30 \mathrm{~m})$ and the complex active channel shape. The maximum classified area of the active channel is $13.5 \mathrm{~km}^{2}$, with $55.3 \%$ of the area having an occurrence frequency $>50 \%$, and $21.3 \%$ of the area having an occurrence frequency $>90 \%$. Analysis has been repeated for the Cagayan River study reach, where the maximum classified area of the active channel is considerably larger $\left(191 \mathrm{~km}^{2}\right)$, with $61.2 \%$ of the area having an occurrence frequency $>50 \%$, and $40.0 \%$ of the area having an occurrence frequency $>90 \%$. In detecting large-scale planimetric change for the Cagayan River, meander expansion (erosion and accretion) and cutoffs were shown. Relatively narrow inputs $(<200 \mathrm{~m})$ at tributary junctions resulted in some temporal inconsistency in the classification procedure.

\subsection{Active channel centerline analysis - RivMAP application}

Here, we focus on the $135 \mathrm{~km}$ reach of the Cagayan River and apply the RivMAP toolbox for centerline analysis (Schwenk et al., 2017). 25 of the 32 annual active channel masks were included for analysis (1988 - 2019), with fragmented binary masks omitted (caused by persistent cloud cover, especially for years with less available Landsat imagery).

Annually resolved active channel centerlines from application of RivMAP show the complex and active morphodynamics for the Cagayan River (Figure 5). Centerline analysis adds quantitative detail to the geomorphic interpretations from Section 3.1. Here, migration rate is calculated from the migrated area divided by the centerline length. For the entire study reach over the 31 year time-period, the average active channel migration rate was $17.5 \mathrm{~m} \cdot \mathrm{a}^{-1}$. The minimum rate was $7.7 \mathrm{~m} \cdot \mathrm{a}^{-1}(1988)$ and the maximum rate was $37.0 \mathrm{~m} \cdot \mathrm{a}^{-1}(2005)$. Locally, however, the migration rate will vary. The middle section of the study reach $(45-85 \mathrm{~km}$ downstream $)$ appears most active, with $>1 \mathrm{~km}$ lateral shifts in the centerline position (especially at meander cutoffs) between 1988 and 2019. It should be noted that the average migration rate is of the same order of magnitude as the Landsat pixel size $(30 \mathrm{~m})$. The migration rates calculated for the study reach are comparable to the migration rates reported by Dingle et al. (2019) for an $\sim 85$ $\mathrm{km}$ reach of the Cagayan and Pinacanauan de Ilagan Rivers (up to $30 \mathrm{~m}^{-1} \mathrm{a}^{-1}$ ). The previous analysis used manually digitized channel bank positions from individual satellite images in 1973, 1990, 2001, 2008 and 2017. The current analysis uses semi-automatically extracted active channel masks resolved at annual intervals. The next steps will be to validate the classification datasets, before undertaking uncertainty analysis on the planimetric change (Donovan et al., 2019). Then, detailed investigation of the spatiotemporal distribution of migration rates, rather 
than reach averaged rates, can be calculated for an improved process-understanding of dynamisms and river behavior.

Figure 4. Active channel for the Bislak River (near Bacarra, $18^{\circ} 15^{\prime} 15.5^{\prime \prime} \mathrm{N} 120^{\circ} 36^{\prime} 46.5^{\prime \prime} \mathrm{E}$ ) in 1989 and 2019 (blue $=$ active channel; black $=$ noise removed, orange star $=$ Bacarra $)$. 
1989
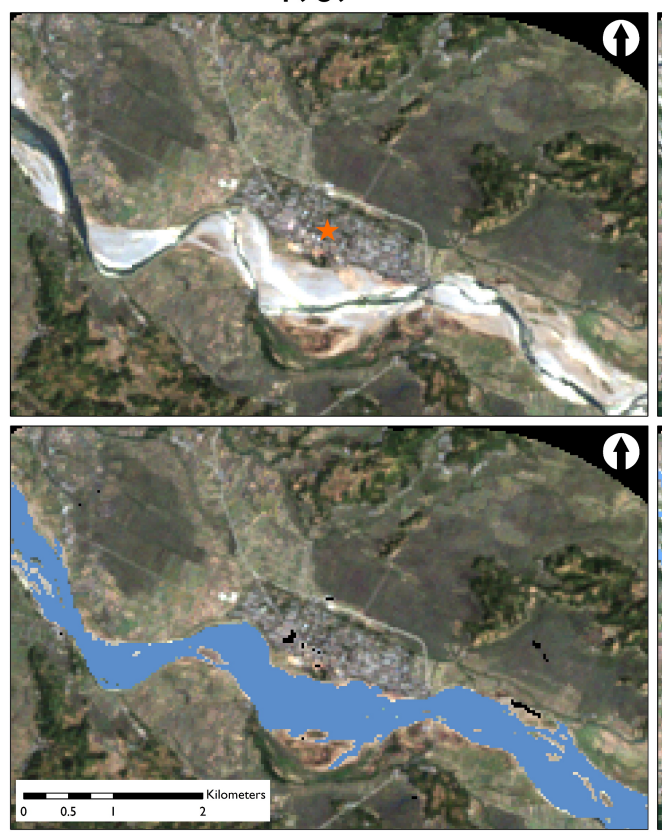

2019
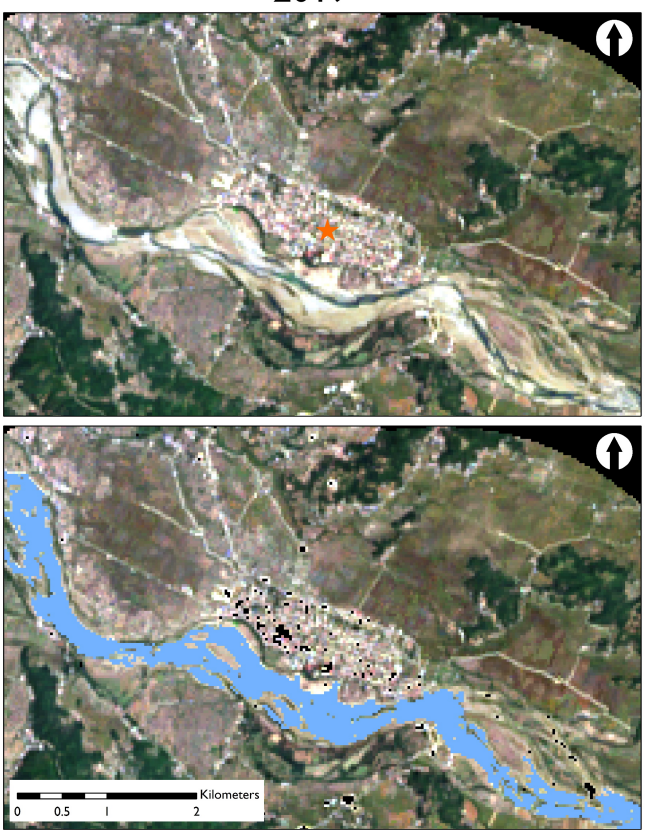

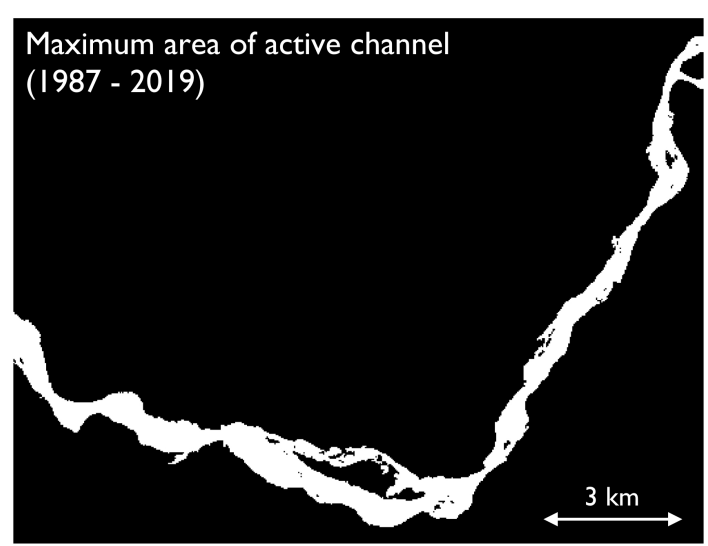

8. Downstream

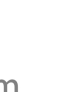

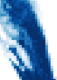
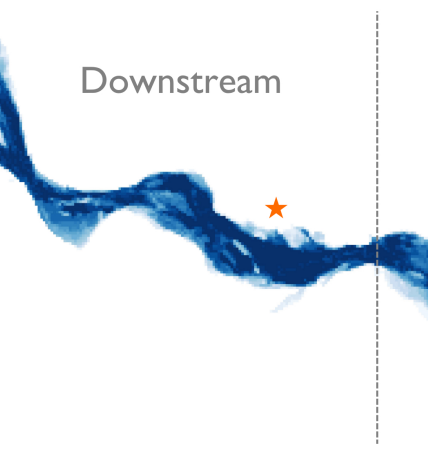

Middle

Upstream

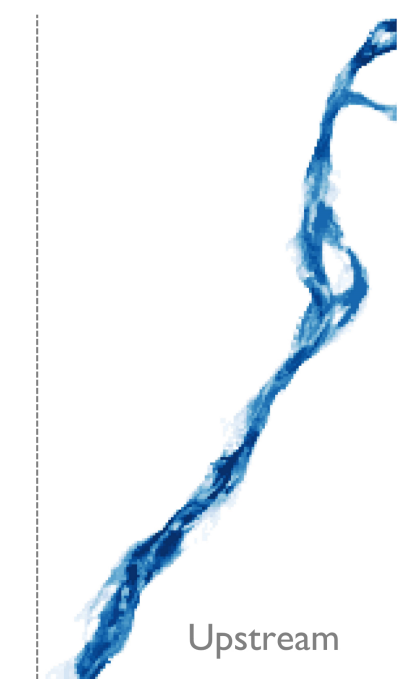

$0 \%$

$50 \%$

Active channel occurrence (1987 - 2019) 

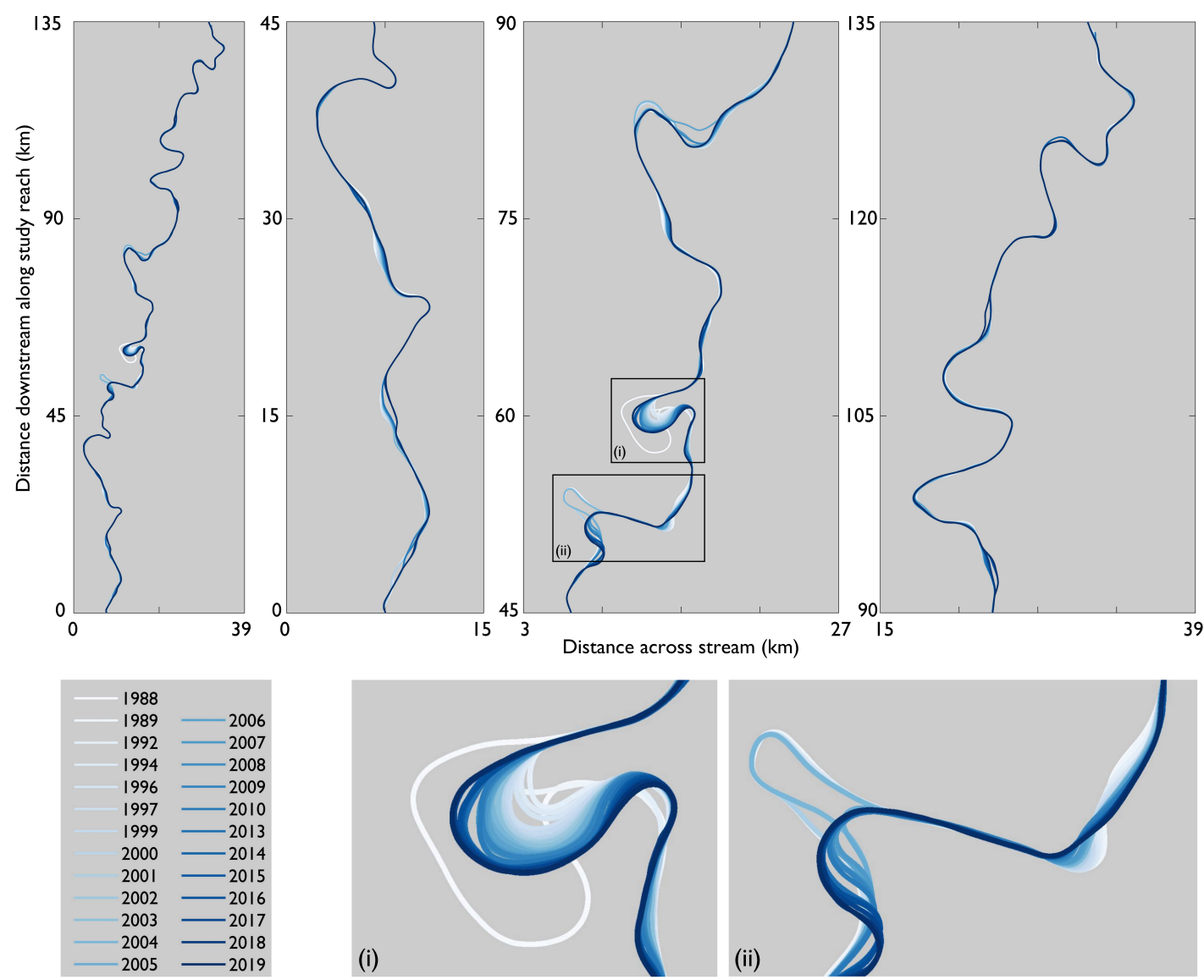

Figure 5. Centerlines for the Cagayan River. Zoom views show the complex migration patterns and cutoffs at (i) $17^{\circ} 47^{\prime} 04.4^{\prime \prime} \mathrm{N} 121^{\circ} 41^{\prime} 49.3^{\prime \prime} \mathrm{E}$ and (ii) $17^{\circ} 51^{\prime} 45.0^{\prime \prime} \mathrm{N} 121^{\circ} 39^{\prime} 38.5^{\prime \prime} \mathrm{E}$. Total centerline length $=\sim 225 \mathrm{~km}$.

\section{CONCLUSIONS}

Active channel change has been investigated over four decades for two tropical river systems in the Philippines using Google Earth Engine and image analysis techniques. We demonstrate:

1. The ability to generate and extract annual active channel masks, using established multiple spectral indices. We demonstrate a semi-automated workflow that takes advantage of cloud masking and temporal compositing within the GEE environment to resolve annual active channels from $\sim 30$ years of Landsat satellite imagery.

2. The application of image analysis techniques to map active channel occurrence frequency, aiding geomorphic interpretations e.g. infrequent activation/disconnection of a secondary chute channel on the Bislak River.

3. Application of the RivMAP toolbox (Schwenk et al., 2017) for centerline change analysis. For the Cagayan River, the reach averaged migration rate ranged from $7.7 \mathrm{~m}^{-1} \mathrm{a}^{-1}$ in 1988 to $37.0 \mathrm{~m} \cdot \mathrm{a}^{-1}$ in 2005 (average $=17.7 \mathrm{~m} \cdot \mathrm{a}^{-1}$ ). The SCREAM package of Rowland et al. (2016) would offer a complementary analysis application in multithreaded river systems. SCREAM uses a bank-based reference frame for analyzing complex channel systems.

4. Application challenges, including: (i) discontinuous active channel masks; (ii) the need to validate classified data; and, (iii) the need for uncertainty analysis when assessing planimetric and morphodynamic change. Preliminary results show that the reach averaged migration rates are of the same order of magnitude as pixel size. 
The ability of these tools to provide multi-temporal data over large river reaches will enable theories of geomorphic change to be tested, and the re-assessment of some classic concepts in fluvial geomorphology such as river channel pattern classification.

\section{REFERENCES}

Bertoldi, W., Drake, N. A. \& Gurnell, A. M. 2011. Interactions between river flows and colonizing vegetation on a braided river: exploring spatial and temporal dynamics in riparian vegetation cover using satellite data. Earth Surface Processes and Landforms, 36, 1474-1486.

Dingle, E. H., Paringit, E. C., Tolentino, P. L. M., Williams, R. D., Hoey, T. B., Barrett, B., Long, H., Smiley, C. \& Stott, E. 2019. Decadal-scale morphological adjustment of a lowland tropical river. Geomorphology, 333, 30-42.

Donchyts, G., Baart, F., Winsemius, H., Gorelick, N., Kwadijk, J. \& Van De Giesen, N. 2016. Earth's surface water change over the past 30 years. Nature Climate Change, 6, 810-813.

Donovan, M., Belmont, P., Notebaert, B., Coombs, T., Larson, P. \& Souffront, M. 2019. Accounting for uncertainty in remotely-sensed measurements of river planform change. Earth-Science Reviews, 193, 220-236.

Edmonds, D. A., Hajek, E. A., Downton, N. \& Bryk, A. B. 2016. Avulsion flow-path selection on rivers in foreland basins. Geology, 44, 695-698.

Foga, S., Scaramuzza, P. L., Guo, S., Zhu, Z., Dilley, R. D., Beckmann, T., Schmidt, G. L., Dwyer, J. L., Joseph Hughes, M. \& Laue, B. 2017. Cloud detection algorithm comparison and validation for operational Landsat data products. Remote Sensing of Environment, 194, 379-390.

Fryirs, K. A., Wheaton, J. M., Bizzi, S., Williams, R. \& Brierley, G. J. 2019. To plug-in or not to plug-in? Geomorphic analysis of rivers using the River Styles Framework in an era of big data acquisition and automation. WIREs Water, 6, e1372.

Gorelick, N., Hancher, M., Dixon, M., Ilyushchenko, S., Thau, D. \& Moore, R. 2017. Google Earth Engine: Planetary-scale geospatial analysis for everyone. Remote Sensing of Environment, 202, 18-27.

Gurnell, A. M., Bertoldi, W., Tockner, K., Wharton, G. \& Zolezzi, G. 2016. How large is a river? Conceptualizing river landscape signatures and envelopes in four dimensions. WIREs Water, 3, 313-325.

Isikdogan, F., Bovik, A. \& Passalacqua, P. 2017. RivaMap: An automated river analysis and mapping engine. Remote Sensing of Environment, 202, 88-97.

Manners, R. B., Schmidt, J. C. \& Scott, M. L. 2014. Mechanisms of vegetation-induced channel narrowing of an unregulated canyon river: Results from a natural field-scale experiment. Geomorphology, 211, 100-115.

Marcus, W. A. \& Fonstad, M. A. 2010. Remote sensing of rivers: the emergence of a subdiscipline in the river sciences. Earth Surface Processes and Landforms, 35, 1867-1872.

Monegaglia, F., Zolezzi, G., Güneralp, I., Henshaw, A. J. \& Tubino, M. 2018. Automated extraction of meandering river morphodynamics from multitemporal remotely sensed data. Environmental Modelling \& Software, 105, 171-186.

Pavelsky, T. M. \& Smith, L. C. 2008. RivWidth: A Software Tool for the Calculation of River Widths From Remotely Sensed Imagery. IEEE Geoscience and Remote Sensing Letters, 5, 70-73.

Pekel, J.-F., Cottam, A., Gorelick, N. \& Belward, A. S. 2016. High-resolution mapping of global surface water and its long-term changes. Nature, 540, 418-422.

Rowland, J. C., Shelef, E., Pope, P. A., Muss, J., Gangodagamage, C., Brumby, S. P. \& Wilson, C. J. 2016. A morphology independent methodology for quantifying planview river change and characteristics from remotely sensed imagery. Remote Sensing of Environment, 184, 212-228.

Schwenk, J., Khandelwal, A., Fratkin, M., Kumar, V. \& Foufoula-Georgiou, E. 2017. High spatiotemporal resolution of river planform dynamics from Landsat: The RivMAP toolbox and results from the Ucayali River. JGR: Earth and Space Science, 4, 46-75.

Syvitski, J. P. M., Vörösmarty, C. J., Kettner, A. J. \& Green, P. 2005. Impact of Humans on the Flux of Terrestrial Sediment to the Global Coastal Ocean. Science, 308, 376-380.

Tolentino, P. L. M., Poortinga, A., Kanamaru, H., Keesstra, S., Maroulis, J., David, C. P. C. \& Ritsema, C. J. 2016. Projected Impact of Climate Change on Hydrological Regimes in the Philippines. PLOS ONE, 11, e0163941. 
Yang, X., Pavelsky, T. M., Allen, G. H. \& Donchyts, G. 2019. RivWidthCloud: An Automated Google Earth Engine Algorithm for River Width Extraction From Remotely Sensed Imagery. IEEE Geoscience and Remote Sensing Letters, 1-5.

Zou, Z., Xiao, X., Dong, J., Qin, Y., Doughty, R. B., Menarguez, M. A., Zhang, G. \& Wang, J. 2018. Divergent trends of open-surface water body area in the contiguous United States from 1984 to 2016. Proceedings of the National Academy of Sciences, 115, 3810-3815. 